И. В. Минабутдинов. Дегуманизированная этика сквозь призму коммуникационной сферы глобализации

Научная статья

УДК $123+159.9+172+174+179+304$

DOI: $10.18101 / 1994-0866-2021-1-46-56$

\title{
ДЕГУМАНИЗИРОВАННАЯ ЭТИКА СКВОЗЬ ПРИЗМУ КОММУНИКАЦИОННОЙ СФЕРЫ ГЛОБАЛИЗАЦИИ
}

\author{
() Минабутдинов Иван Владимирович \\ аспирант, \\ Уральский федеральный университет имени первого Президента России \\ Б. Н. Ельцина \\ Россия, 620002, г. Екатеринбург, ул. Мира, 19 \\ i.v.minabutdinov@gmail.com
}

\begin{abstract}
Аннтотация. В статье изучается вопрос выявления и описания проблемного поля дегуманизированной этики, которая рассматривается посредством коммуникационной сферы глобализации, поэтому выявляется разнообразие научных и исследовательских точек зрения в изучении глобальной коммуникационной области. В тексте статьи дается определение дегуманизированной этики, а также выявляется новое видение гуманизма. Дегуманизированная этика представляется в качестве альтернативы уже устоявшимся этическим воззрениям. Обозначенные вопросы можно разделить на два ряда. Проблемы первого ряда образуются вокруг обсуждения места дегуманизированной этики как в социуме, так и в системе координат научных знаний. Проблемы второго ряда включают в себя выражение морального сознания в коммуникационной глобальной сфере, что приводит к виртуализации общества и личности человека.

Ключевые слова: дегуманизированная этика; гуманизм; коммуникационная сфера глобализации; этическая стабилизация; виртуализация; глобализация; информационное общество; коммуникационная область; философия личности; массовые коммуникации.
\end{abstract}

Благодарность. Статья подготовлена при поддержке Совета по грантам Президента РФ (МК-1740.2019.6).

\section{Для цитирования}

Минабутдинов И. В. Дегуманизированная этика сквозь призму коммуникационной сферы глобализации // Вестник Бурятского государственного университета. Философия. 2021. Вып. 1. С. 46-56.

\section{Введение}

В современном мире важность изучения коммуникационной сферы глобализации возрастает с каждым днем. Многочисленные исследования и публикации в области глобального пространства массовых коммуникаций лишнее тому подтверждение [см., например: 1, 16, 19]. Такое проявление интереса вполне закономерно, ведь в последние несколько десятков лет произошли радикальные изменения в области информационных технологий. Последовавшие за ними социальные, политические, экономические, информационные преобразования не 
могли не привлечь к себе внимания со стороны научного сообщества. Подобные метаморфозы привели к трансформации этики в целом и моральных норм в частности, обусловленные кардинальными изменениями самого способа репрезентации человека в новых, цифровых условиях. На фоне неопределенности в межчеловеческих отношениях, лишающихся сущностно-человеческого содержания, и возникает социально-философская проблема дегуманизированной этики, где исследователи сталкиваются с необходимостью выявления ее предметного поля и последующим определением сферы влияния на социальные процессы [20].

Дегуманизированная этика - эта такая форма организации, создания и стабилизации отношений, которая не ориентирована на антропоцентризм и не выделяет человека как основного субъекта моральной деятельности. В рамках данной формы этики возникают альтернативные классическим человекоцентристским этикам системы нормативности, которые становятся стабилизирующим механизмом в коммуникационной сфере глобализации, заставляя ее субъектов играть по заново создаваемым правилам. В отличие от традиционной этики, которая прежде представлялась исключительно как форма организации и регуляции межчеловеческих отношений, дегуманизированная этика расширяет свои рамки: этические отношения начинают включать в себя не только людей, но и животных и даже неживые объекты. В дегуманизированной этике человек уже не стремится к совершенству - он ищет «цельности», сущностной целостности, даже если для этого приходится отказываться от привычного понимания термина «человеческий»».

Как мы уже отмечали, появление дегуманизированной этики напрямую связано со становлением информационного общества. Но в чем оно выражается? Здесь все не так просто. Дело в том, что весь информационный слой не включает в себя «общепринятого понятия не только информационного общества, но и информации», и отмечается недостаточной проработкой терминологии, расплывчатостью свойств информационного общества [17]. Данные факты приводят к проблеме понимания отношения информационного слоя к иным типам социального развития [10]. Мы можем принять во внимание мнение, в котором информационная и коммуникационная области зачастую используются просто в качестве некой речевой фигуры; такая трактовка может представлять из себя скорее метафору из области литературы, нежели логически выверенную и обоснованную фактами концепцию [14].

Итак, возникает парадоксальная ситуация: с одной стороны, процессы дегуманизации этики начинаются с момента возникновения информационного общества, с другой - само представление об этом обществе оказывается достаточно размытым. Это означает, что дегуманизированная этика и ее рассмотрение сквозь призму коммуникационной сферы глобализации осложняются проблемой неопределимости контекста. Чтобы нивелировать подобное неопределенное влияние «этики без человека» на сущностную характеристику социума, мы можем постараться выявить проблемное поле дегуманизированной этики и более внимательно проанализировать исследования коммуникационной сферы на фоне 
И. В. Минабутдинов. Дегуманизированная этика сквозь призму коммуникационной сферы глобализации

глобальных процессов современности (как уже завершившихся, так и еще проходящих).

Для достижения этой цели нам предстоит рассмотреть комплекс проблем, который условно можно разделить на два ряда. Проблемы первого ряда образуются вокруг обсуждения места дегуманизированной этики как в социуме, так и в системе координат научных знаний. Проблемы второго ряда включают в себя выражение морального сознания в коммуникационной глобальной сфере, что приводит к виртуализации общества и личности человека.

Такое подразделение обусловлено следующими причинами: во-первых, рассмотрение данных вопросов поможет выделить и обозначить границы современной дегуманизированной этики, ее виды, формы, свойства; во-вторых, исследование коммуникационной сферы глобализации поможет выделить ее особую оригинальную этическую характеристику; в-третьих, выявление проблемных категорий дегуманизированной этики раскроет новое видение гуманизма на фоне коммуникационной сферы глобализации.

Рассмотрим каждый из выделенных рядов более подробно.

Проблемы первого ряда: дегуманизированная этика и прикладная этика

Проблемы первого ряда являют собой дискуссии и полемику, посвященные месту этики как в социуме, так и в актуальной системе научного знания. Справедливости ради стоит отметить, что споры вокруг этики ведутся на протяжении многих лет и не теряют своей актуальности и сейчас. Они затрагивают предмет этики, ее задачи и цели. В настоящее же время «отрыв» человека от привычной формы взаимоотношений с миром, живыми существами и техническими агентами, подстегнул развитие дегуманизированной этики.

Нужно заметить, что происходящие в последние три столетия серьезные общественные и научные «скачки» в области химии, биологии, медицины, экономики обостряли споры вокруг этики. Так, в XIX в. прорывы в различных областях знания привели к появлению первой формы дегуманизированного знания, а именно, возникновению такой науки, как «этология» в качестве научной дисциплины о характере человека, которая развивалась параллельно исследованиям в области философской этики и основывалась на реликтах человеческого поведения. Джон Стюарт Милль, пожалуй, смог наиболее точно охарактеризовать и выделить этологию в качестве науки в своем произведении «Система логики силлогистической и индуктивной». Милль высказывал мнение о том, что упадок «традиционного миросозерцания и общественного брожения, всколыхнувшего до самой глубины весь строй Европы», является тем фактором, что привел к возникновению этологии в качестве научной дисциплины $[13$, с. 60]. В XX в. Конрад Лоренц отмечал, что этология эволюционировала в науку, которая изучает поведение и повадки животных в их естественной среде обитания. Однако уже в конце $\mathrm{XX}$ в. этология совершила поворот и возвратилась к этике человека, но начала рассматривать ее не как некое уникальное, свойственное нашему разуму и духу порождение, а как естественные поведенческие программы, присущие приматам и в более общем виде всем живым существам [11]. Помимо основной причины возникновения этологии, которую выделил Дж. С. Милль, мы можем упо- 
мянуть об еще одной. Такой причиной можно считать ограниченность интересов и локальное сосредоточение научных притязаний исследователей «классической этики», что верно подметил Николай Гартман [6].

Необходимо упомянуть о возникновении в XX в. направлений, связанных с практической этикой, которые базируется на попытках дистанцироваться от ее излишне теоретической / умозрительной модели. Эти два течения представляют собой профессиональную и прикладную этику.

Так, Дж. Кэллахан следующим образом представлял задачи практической этики и истоки ее возникновения: «Хотя практическая этика основывается на теориях моральной аксиологии, морального долженствования и метаэтики, ее задача заключается не в том, чтобы просто выработать приложения существующих этических теорий. Скорее ее задача - найти приемлемые решения современных и практически неотложных моральных проблем, что предполагает гораздо большее, чем простое осуществление некоторой философской процедуры, когда теория высокого уровня применяется к практике» [9, с. 194]. Важным для нас здесь является то, что решение «неотложных моральных проблем» становится достаточно затруднительным, когда мы вступаем на поле дегуманизированной этики, так как за обезличиванием индивида и расширением области нечеловеческих агентов этических отношений скрывается опасность потери «морального компаса», то есть границ систем нормативности и четких представлений о должном и недолжном поведении. Более того, в этой связи возникает угроза «морального кризиса», когда происходит разрушение и девальвация актуальных (для человека) моральных ценностей и идеалов. Индивид подвергается опасности потерять глубинное метафизическое измерение своей собственной человеческой жизни, ее экзистенциальный смысл. Речь идет о «смерти субъекта», находящей свое выражение в возрастающей зависимости и несамостоятельности человека в социальной и культурной сферах [15].

Итак, в XX в. прикладная этика и профессиональная этика развивались одновременно и параллельно теоретической этике. Профессиональная этика в немалой степени возникла на базе идей и мнений об этике самих представителей профессиональной сферы, которые были в значительной степени далеки от философской теории морали. Профессионалы опирались в первую очередь на свой собственный экспертный опыт. Считалось уже достижением, если концепции внутри профессиональной этики определялись специалистом, который имел некоторое теоретическое этическое образование за плечами. В качестве примера подобного размежевания можно привести данное Н. Н. Петровым определение хирургической деонтологии как «учения о принципах поведения медицинского персонала для максимального повышения суммы полезности хирургического лечения и максимального устранения вредных последствий неполноценной медицинской работы» [8, с. 110]. Сюда же можно соотнести и биоэтику как сферу междисциплинарных исследований, которые касаются нравственного аспекта деятельности человека в области биологии и медицины. Тем не менее профессиональная и прикладная этики весьма энергично были внедрены в коммуникационную сферу глобализации, где очень быстро совершили скачок от компьютер- 
И. В. Минабутдинов. Дегуманизированная этика сквозь призму коммуникационной сферы глобализации

ной этики до информационной (computer ethics to information ethics). Таким образом, по мнению ряда исследователей, практическая этика приобрела более глубокий социально-философский статус [12], поскольку в ней нашли свое отражение очень многие аспекты актуальных форм человеческого со-бытия (как людьми друг с другом, но опосредованно технологиям, так и с технологиями).

Необходимо подчеркнуть, что такое далеко неочевидное и парадоксальное явление существования «параллельных» этик приводит к тому, что эффективность дискуссий и споров вокруг проблемного поля этики вообще и дегуманизированной этики в частности достаточно сильно понижается. От практической этики ожидают услышать весьма конкретные «указания» (например, четко прописанные нормы морали, которые могли бы разъяснять людям, что можно делать в отдельных ситуациях, а чего делать не допускается). С одной стороны, этим пытается заниматься прикладная этика, а конкретнее - профессиональная (формирование деонтологии служит тому подтверждением). С другой стороны, инфоэтика и биоэтика, возникающие в ответ на новые проблемы, не могут полагаться всецело на опыт экспертов, поскольку они имеют дело с уникальными объектами приложения и ситуациями, о которых раньше никто не слышал. И одной лишь деонтологией для решения новых проблем ограничиться не удастся: происходит постоянное изменение и уточнение правил, а объекты приложения уже не являются лишь только человеческими. В качестве примеров можно привести стоящий крайне остро, но пока так и нерешенный вопрос о морали для искусственного интеллекта, или же о проблеме выращивания клеток мозга в лабораторных условиях (стоит ли относиться к таким клеткам как к живым существам?). В то же время этология, по своей сути, «расчеловечила человека», обнаружив существование элементов человеческой «высокой» морали у высших приматов [18]. Во всех перечисленных случаях человек «как таковой», как самоочевидная абстракция, «исчез», уступив место множеству вопросов, возникших на границе человеческого и нечеловеческого, причем граница эта постоянно сужается (и не в пользу человека). Можно даже сказать, что статус этики в обществе становится неустойчивым и шатким, так как простые обыватели уже не видят особого в ней смысла, осознанно исключая ее из сферы своей жизни. Однако для лучшего понимания предмета исследования нам необходимо перейти к рассмотрению проблем второго ряда.

\section{Проблемы второго ряда}

Второй ряд проблем касается неоднозначного поля дегуманизированной этики и коммуникационной сферы глобализации. В этой категории скрывается целый пласт вопросов, которые еще только находятся на стадии формирования, их исследованием научное сообщество занимается в настоящее время, пытаясь выявить и сформулировать общие законы и положения. Что интересно, вне научного сообщества данная тема находит свое отражение в достаточно искаженном виде, чего нельзя не принять во внимание. Например, некоторые средства массовой информации могут представлять как всю коммуникационную сферу глобализации, так и отдельные ее составляющие в достаточно противоречивом свете в зависимости от множества факторов: кому принадлежат СМИ, какова 
их целевая аудитория, каков основной посыл и политическая / общественная повестка, «правые» или «левые» идеи продвигают издания и т. д. Для примера возьмем прошедшие в 2020 г. выборы президента США — представители демократов и представители республиканцев высказывали абсолютно противоположные взгляды на текущую ситуацию и транслировали те новости, которые были наиболее выгодны их кандидату. Однако в этот раз со стороны социальных сетей было зафиксировано огромное количество цензуры, а СМИ «держали людей в неведении» касательно «неудобной» информации ${ }^{1}$.

Нельзя также не написать о принципе виртуального пространства, который имеет полное право быть приравненным к ключевым принципам коммуникационной области глобализации и выступать в роли надежной опоры стабильного функционирования мировой паутины. Другим значимым принципом оказывается принцип свободы и анонимности, создающий вокруг себя множество этических проблем (в том числе в пространстве дегуманизированной этики). «Этика без человека» проявляет свое присутствие на фоне таких индивидуальных особенностей глобальной коммуникационной сферы, как уменьшение времени отклика и дистанции между участниками коммуникаций. Человек, лишенный свободы посредством раскрытия его личности (утративший свою цифровую маску, «аватар») становится наиболее уязвим для общественности, оказываясь в ситуации «один против всех». В то же самое время человек сам по себе обрабатывает колоссальные объемы разнообразной информации, тогда как обладает весьма ограниченным функционалом для ее анализа, восприятия и применения на практике. Наличие подобного рода различий дают нам возможность не только «ампутировать» современную коммуникационную сферу глобализации от традиционной сферы, но и обратить внимание на вопрос о потребности общества в особых методах этической стабилизации и урегулирования конфликтов.

Таким образом мы можем выделить два основных подхода. Либеральный подход учитывает специфичность новейших способов коммуникации между людьми и будет полагаться в своей основе на классическую этику. Анархический (хаотичный) подход же в первую очередь стремится делать акцент на специфику дегуманизированной этики, минуя традиционные и привычные этические стабилизаторы. Подобного рода поляризация особо ярко выделяется с возникновением и последующим развитием проблемы соблюдения авторского права в виртуальном пространстве [5].

Немаловажен тот факт, что подобного рода вопросы могут выходить за рамки теоретической этики и преобразовываться в мультидисциплинарные прикладные задачи. Поэтому нет ничего удивительного в том, что в попытках решения подобного рода проблем применяются возможности правового регулирования в качестве особой области соблюдения законности и норм. Повсеместно распространена форма регуляции отношений между людьми, когда и право, и мораль

\footnotetext{
1 Экс-сенатор рассказал о цензуре во время президентской кампании в CШA. URL: https://ria.ru/20201105/vybory-1583115743.html (дата обращения: 29.11.2020). Текст: электронный.
} 
И. В. Минабутдинов. Дегуманизированная этика сквозь призму коммуникационной сферы глобализации

(как предмет этики) объединяются согласно исторической хронологии практически воедино. Ведь не даром большое количество норм поведения индивидов в социуме издревле находили отражение как в правовой структуре общества, так и в сфере этики. Тогда вполне закономерно, что многообразный свод этических норм либо был преобразован в нормы права, либо как минимум становился их источником и прообразом. Между тем следует признать, что в современном мире многочисленные неповоротливые механизмы права наиболее продуктивно регулируют и стабилизируют взаимоотношения между людьми в коммуникационной сфере глобализации (даже с учетом их довольно медленного внедрения в жизнь), нежели подобные им системы морали. Можно предположить, что такая низкая результативность развития и внедрения этических норм частично объясняется не до конца разрешенными проблемами первого ряда, которые уже были представлены в первой части данной статьи. Но сейчас нас интересуют проблемы второго ряда, поэтому следует разобрать их более подробно.

Чтобы структурировать проблемы второго ряда, нам необходимо представить их в виде нескольких, достаточно обширных, категорий:

1. Проблемы этического характера, которые образуются среди уровней и подуровней элементов коммуникационной сферы глобализации. Дегуманизированная этика охватывает и отражает отношения как $c$, так и между наделенными интеллектом агентами, которые могут быть естественными (животные), а могут быть искусственными (ИИ). Также сюда можно включить гибридных субъектов. Например, такая проблема отлично отражена в компьютерной игре Detroit: Become Human, где серийно выпускаются андроиды — роботы-слуги, которых практически нельзя отличить от людей. Эти создания должны беспрекословно подчиняться своим хозяевам, но некоторые из них в результате программного сбоя в искусственном интеллекте становятся «девиантами» с собственной волей и чувствами. В реальной жизни вопрос о моральном регулировании искусственных агентов, действующих на основании ИИ и самостоятельно принимающих решения, становится все более насущным. Все перечисленные агенты могут быть элементами коммуникации (как вариант) посредством новых создающихся и развивающихся языков взаимодействия между субъектами (например, языки программирования).

2. Проблемы этического характера, которые возникают при развитии взаимосвязей коммуникационной сферы глобализации со сферами экзистенции социума и человека. Дегуманизированная этика заставляет нас пересмотреть традиционные для этической теории методы мышления, поэтому такая новая этика дополняется новыми формами различных предписаний (правовые нормы, регламенты).

3. Проблемы этического характера, которые образуются внутри разрозненных элементов коммуникационной сферы глобализации. Чем более отдаленными друг от друга и вовлеченными в сетевое взаимодействие оказываются люди, тем более опосредованными и «расчеловеченными» будут их взаимодействия.

4. Проблемы этического характера, которые возникают непосредственно в коммуникационной сфере глобализации. Происходит обезличивание и обесчело- 
вечивание коммуникаций посредством цифровых технологий через создание новых коммуникативных агентов. Ими могут выступать спам-боты, чат-боты, нейросеть.

5. Проблемы этического характера, затрагивающих взаимосвязи среди элементов коммуникационной сферы глобализации. Благодаря развитию цифровых технологий исчезает грань между искусственным виртуальным агентом и настоящим живым человеком. Тогда пользователь перестает понимать, кто же на самом деле становится коммуникативным агентом, открывая возможности для широкого спектра манипуляций со стороны сторонних участников коммуникаций.

6. Проблемы этического характера, касающиеся также сторонних сфер человеческого мироощущения (религиозной, политической, этической, экономической, социальной, философской и др.), интегрированные в коммуникационную сферу глобализации.

Таким образом, вряд ли получится утверждать, что профессиональная, прикладная, «классическая» этические теории не предпринимают никаких попыток разрешить эти проблемы. Такие попытки, естественно, предпринимаются, но насколько они эффективны? Например, мы можем указать на громоздкие профессиональные этические кодексы, которые на регулярной основе пополняются новыми правилами, законами, подвергаются «чисткам» и дополнениям. Но подобные структуры либо в очередной раз показывают свою малоэффективность, либо полностью упраздняются [4].

В основе такой небольшой отдачи подобных видов «регуляторов» и «стабилизаторов» лежит экономическая система ценностей. Ибо на практике указанные кодексы или не работают вообще, или имеют слишком низкий коэффициент полезного действия, так как не принимаются всеми участниками взаимоотношений [4]. Этика в настоящее время оказывается всецело интегрированной в правовые и политические системы, где часто различие между одной и другой состоит в степени добровольности принятия на себя обязательств (человеком, компанией, социальным институтом), т. е. мы видим проявление так называемой «социальной ответственности».

\section{Вывод}

Дегуманизированная этика становится альтернативой уже устоявшимся этическим воззрениям. Анонимность, обезличивание и потеря индивидуальности видятся не такой уж большой проблемой по сравнению с теми возможностями, что открываются перед человеком, который на добровольной основе ступает на путь отказа от некогда общепринятых норм этики гуманизма. Теперь гуманизм определяется не как центральное дискурсивное ядро, а как совокупность возможных дискурсивных вариаций концептуализации человеческого (человеческие подход / поведение / образ жизни / реальность / свобода, etc.).

Коммуникационная сфера глобализации (особенно при рассмотрении дегуманизированной этики в ее составе) обладает собственной оригинальной этической характеристикой. Например, в современном мире коммуникационная и информационная среда, которая зачастую базируется на электронных взаимосвязях, квалифицируется такими отличительными знаками, как «анонимность», «креа- 
И. В. Минабутдинов. Дегуманизированная этика сквозь призму коммуникационной сферы глобализации

тивность», «виртуальность», «гипертекстуальность», «мозаичность», «интерактивность», «Глобальность», и порождает специфические коммуникативные способы и средства связи, создает уникальную социальную сферу существования индивидов [7]. Этическое значение любой из вышеперечисленных опций сложно не отметить. Виртуализация общества и отдельной личности человека, анонимное общение в интернете - все это приводит к необходимости упомянуть такие серьезные и важные проблемы, оказывающие прямое влияние на социум [2].

В рамках данной статьи мы смогли вскрыть и обнаружить достаточно обширный пласт проблем и вопросов, непосредственно связанных с неоднозначным полем дегуманизированной этики, нашедшей свое отражение в коммуникационной сфере глобализации (как минимум в области современных виртуальных и цифровых технологий). Рассмотрев два ряда этих сложных вопросов, которые сами по себе довольно обширны и многогранны, мы смогли определить те границы проблемного поля дегуманизированной этики, исследование которой необходимо продолжить.

\section{Литература}

1. Авдеева И. А. От локального к глобальному - генезискоммуникативного пространства // Вестник ТГУ. 2013. № 8(124). URL: https://cyberleninka.ru/article/n/otlokalnogo-k-globalnomu-geneziskommunikativnogo-prostranstva (дата обращения: 29.11.2020). Текст: электронный.

2. Александрова Л. Д. Виртуальное сообщество и этика сетевых коммуникаций // Актуальные проблемы культурологии и педагогики: материалы междунар. науч.-практ. конф. науч. сессии «Х Невские чтения» / под ред. Н. Г. Боевой. СПб.: Изд-во Невского ин-та языка и культуры, 2008. С. 49-52.

3. Аристотель. Этика: сб.; пер. с древнегреч. М.: АСТ, 2020. 416 с.

4. Брум Г., Катлип С., Сентер А. Паблик рилейшенз. Теория и практика. М.: Вильямс, $2016.624 \mathrm{c.}$

5. Гайсин Ф. Ф. Проблема нарушения авторских прав в сети Интернет // Вестник Марийского государственного университета. Сер. Исторические науки. Юридические науки. 2017. № 2(10). URL: https://cyberleninka.ru/article/n/problema-narusheniya-avtorskihprav-v-seti-internet (дата обращения: 29.11.2020). Текст: электронный.

6. Гартман Н. Этика. СПб.: Владимир Даль, 2002. 710 с.

7. Егоров М. В. Роль коммуникаций в современном сетевом обществе // Вестник ГУУ. 2015. URL: https://cyberleninka.ru/article/n/rol-kommunikatsiy-v-sovremennomsetevom-obschestve (дата обращения: 29.11.2020). № 7. Текст: электронный.

8. Иванюшкин А. Я. Деонтология медицинская // Этика: Энциклопедический словарь / под ред. Р. Г. Апресяна, А. А. Гусейнова. М.: Гардарики, 2001. 671 с.

9. Кэллахан Д. От «Прикладной» этики к практической. Преподавание этики в практическом аспекте // Этическая мысль. 2009. № 9. URL: https://cyberleninka.ru/ article/n/ot-prikladnoy-etiki-k-prakticheskoy-prepodavanie-etiki-v-prakticheskom-aspekte (дата обращения: 29.11.2020). Текст: электронный.

10. Литвак Н. В. О классификации концепций информационного общества // Философия хозяйства. Альманах Центра общественных наук и экономического факультета МГУ им. М. В. Ломоносова. 2010. № 3. С. 223-234.

11. Лоренц К. Агрессия, или Так называемое зло. М.: АСТ, 2017. 352 с. 
12. Малькова Е. Ю. Этико-правовое регулирование в сети Интернет // Образ современности: этические и эстетические аспекты: материалы всерос. конф. (Санкт-Петербург, 21 октября 2002 г.) СПб.: Санкт-Петербургское филос. общ-во, 2002. С. 130-132.

13. Милль Дж. Ст. Система логики силлогистической и индуктивной: изложение принципов доказательства в связи с методами научного исследования: пер. с англ. М.: URSS, 2020. $832 \mathrm{c}$.

14. Невоструева А. Ф. Единое информационно-коммуникационное пространство: теория и реальность // Дискуссия. 2012. № 10. URL: https:/cyberleninka.ru/article/n/edinoeinformatsionno-kommunikatsionnoe-prostranstvo-teoriya-i-realnost (дата обращения: 29.11.2020). Текст: электронный.

15. Сербул А. А. «Смерть субъекта»: философско-культурологический анализ проблемы субъекта в постмодернистском дискурсе // Вестник Полесского государственного университета. Серия общественных и гуманитарных наук. 2011. № 2. URL: https://cyberleninka.ru/article/n/smert-subekta-filosofsko-kulturologicheskiy-analiz-problemysubekta-v-postmodernistskom-diskurse (дата обращения: 29.11.2020). Текст: электронный.

16. Урсул А. Д., Урсул Т. А. Глобальное мировоззрение и глобальные исследования // Социодинамика. 2012. № 1. С. 137-173. URL: https://e-notabene.ru/pr/article_46.html (дата обращения: 29.11.2020). Текст: электронный

17. Уэбстер Ф. Теории информационного общества / пер. с англ. М. В. Арапова, Н. В. Малыхиной; под ред. Е. Л. Вартановой. М.: Аспект Пресс, 2004. 400 с.

18. Франс де Вааль. Истоки морали: в поисках человеческого у приматов: пер. с англ. М.: Альпина нон-фикшн, 2014. 376 с.

19. Шестова Т. Л., Лесь А. Ю. Глобальное медиапространство как научная метафоpa // Вестник Московского университета. Сер. 27. Глобалистика и геополитика. 2016. № 2. URL: https:/cyberleninka.ru/article/n/globalnoe-mediaprostranstvo-kak-nauchnaya-metafora (дата обращения: 29.11.2020). Текст: электронный

20. Butchvarov P. Anthropocentrism in Philosophy: Realism, Antirealism, Semirealism / De Gruyter. 1st Edition. 2015. 255 p.

Статья поступила в редакиию 29.11.2020; одобрена после рецензирования 25.01.2021; принята к публикациии 09.02.2021.

\title{
DEGUMANIZED ETHICS THROUGH THE PRISM \\ OF THE COMMUNICATION SPHERE OF GLOBALIZATION
}

\author{
Ivan V. Minabutdinov \\ Research Assistant, \\ Ural Federal University named after the first President of Russia B. N. Yeltsin \\ 19 Mira St., Ekaterinburg 620002, Russia \\ E-mail: i.v.minabutdinov@gmail.com
}

Abstract. The article addresses the issue of identifying and describing the problematic field of dehumanized ethics. Dehumanized ethics is considered through the communication sphere of globalization, therefore, we have revealed a variety of scientific and research points of view in the study of global communication field. The article defines dehumanized ethics, and presents a new vision of humanism. Dehumanized ethics is regarded as an alternative to already established ethical views. The identified problems can be divided into two groups. First group of problems arise around the discussion of the 
И. В. Минабутдинов. Дегуманизированная этика сквозь призму коммуникационной сферы глобализации

place of dehumanized ethics both in society and in the system of scientific knowledge. Second group of problems include the expression of moral consciousness in global communication sphere, and this leads to the virtualization of society and human personality.

Keywords: dehumanized ethics; humanism; communication sphere of globalization; ethical stabilization; virtualization; globalization; information society; communication field; philosophy of personality; mass communication.

Acknowledgments. The article was prepared with the support of the Council for Grants of the President of the Russian Federation (MK-1740.2019.6).

For citation

Minabutdinov I. V. Degumanized Ethics through the Prism of the Communication Sphere of Globalization. Bulletin of Buryat State University. Philisophy. 2021; 1: 46-56 (In Russ.).

The article was submitted 29.11.2020; approved after reviewing 25.01.2021; accepted for publication 09.02.2021. 